\title{
Heart rate, employment status, and prevalent ischaemic heart disease confound relation between cereal fibre intake and blood pressure
}

\author{
MICHAEL J LICHTENSTEIN, ${ }^{1}$ MICHAEL L BURR,${ }^{2}$ ANN M FEHILY, ${ }^{2}$ AND JOHN \\ W G YARNELL ${ }^{2}$ \\ From the Division of General Internal Medicine, ${ }^{1}$ B-2106 Medical Center North, Vanderbilt University Medical \\ Center, Nashville, Tennessee 3732 USA; and the MRC Epidemiology Unit, ${ }^{2} 4$ Richmond Road, Cardiff CF2 $3 A S$, \\ Wales
}

SUMMARY Cross sectional data from a survey of 2512 men aged 45-49 years were used to examine the confounding effects of heart rate, employment, and ischaemic heart disease (IHD) on the relation between cereal fibre intake and blood pressure. Daily cereal fibre intake (g/day) was associated with systolic pressure $(\mathrm{r}=-0.053, \mathrm{p}<0.01)$, diastolic pressure $(\mathrm{r}=-0.057, \mathrm{p}<0.01)$, and heart rate $(\mathrm{r}=-0.071, \mathrm{p}<0.01)$. The associations were strengthened in employed men and inapparent in ${ }^{\circ}$ unemployed men. Unemployed men had more IHD than employed men. Persons with anyo manifestation of IHD had significantly higher blood pressure and heart rates but ate less cereal fibre $(7.0 v 7.9 \mathrm{~g} /$ day, $\mathrm{p}<0.001)$ than those without IHD, regardless of employment status. In employec men, after adjustment for age, body mass index, prevalent IHD, and heart rate, systolic pressure changed $-0.186 \mathrm{mmHg}(95 \% \mathrm{CI}=-0.362,-0.009)$ and diastolic pressure changed $-0.111 \mathrm{mmHg}$ $(95 \% \mathrm{CI}=0.228,0.005)$ for each gram of cereal fibre eaten daily. The association between cereal fibr and blood pressure was inapparent in unemployed men. Heart rate, employment, and prevalent IHD confound the association between cereal fibre intake and blood pressure. Future work concerning this relationship will have to account for the effects of these variables.

It is necessary to discover the determinants of blood pressure because blood pressure is a principal risk factor for ischaemic heart disease (IHD). Even those determinants having a small effect are important since a reduction in a population's mean blood pressure of 2-3 mmHG could potentially save as many lives as current antihypertensive therapy. ${ }^{1}$ Factors having a small effect on blood pressure may be difficult to detect because of their low order correlations with blood pressure or confounding relations with other variables.

Cereal fibre has been postulated to be a determinant of blood pressure. Some studies have shown an inverse relation between cereal fibre intake and blood pressure, ${ }^{2-4}$ others have not. ${ }^{56}$ The relation between these two factors may have been missed in some studies because they were too small. Alternatively, the apparent link between the two factors is really noncausal and the association arises from confounding variables related to both cereal fibre and blood pressure.

The opportunity was taken to examine data from a large survey to see whether a relation could be found between cereal fibre and blood pressure, and then to see whether any such relation could be explained by employment, prevalent ischaemic heart disease, and heart rate. Our hypothesis was that employed healthier individuals would have lower blood pressures and heart rates but also would eat diets with more cereal fibre.

\section{Methods}

The Caerphilly heart disease study is based on a cohort of 2512 men aged 45-49 years in South Wales. Details of the study aims, methods, and cohort assembly have been published. ${ }^{7}$

Blood pressure, heights, weights, and electrocardiograms (ECG) were obtained and questionnaires were completed at evening clinics. Body mass index was calculated as $\mathrm{kg} / \mathrm{m}^{2}$. Blood pressure was measured by one observer using either a random-zero or regular mercury sphygmomanometer. A single blood pressure recording was taken from the straightened left arm with the person seated. Daily cereal fibre intake was estimated from a food 
Heart rate, employment status, heart disease confound relation between cereal fibre intake and blood pressure 331

frequency questionnaire which had been previously validated against weighed dietary records. ${ }^{8}$

IHD was characterised as "none" or "any manifestation". To have "any manifestation" a subject had to have $(a)$ angina pectoris or possible myocardial infarction from the London School of Hygiene and Tropical Medicine Chest Pain Questionnaire, and/or (b) major or minor Q waves, ST and $T$ wave changes, or left bundle branch block on ECG (Minnesota codes $1 \cdot 1$ to $1 \cdot 3,4 \cdot 1$ to $4 \cdot 4,5 \cdot 1$ to $5 \cdot 3$, and $7 \cdot 1){ }^{7}$

Correlation coefficients were used to examine relations between continuous variables. ${ }^{9}$ Relations between variables and cereal fibre intake were then examined by stratification, presentation of means and standard deviations. Differences between means were compared using an unpaired $t$ test. Multiple linear regression was used to examine the relation between cereal fibre, confounding variables and blood pressure. ${ }^{9}$

\section{Results}

Daily cereal fibre intake estimates were calculated for 2421 subjects. Of these, 2404 had their employment status noted. These groups form the basis for the analysis. Missing values account for slight differences in totals in the tables.

The correlation coefficients between cereal fibre intake, systolic pressure, diastolic pressure, and heart rate for the whole cohort are presented in table 1 . Cereal fibre intake was associated with systolic pressure, diastolic pressure, and heart rate. Age and body mass index were correlated with systolic blood pressure $(r=0.166$ and 0.220 respectively, $p<0.0001)$ but not with cereal fibre intake $(r=-0.026$ and -0.023 respectively). Energy intake (kcal/day) was correlated with cereal fibre intake $(r=0.303$, $\mathrm{p}<0.0001$ ) but not with systolic or diastolic pressure $(r=-0.019$ and -0.028 respectively).

Table 1 Correlation matrix for cereal fibre intake, blood pressure, and heart rate ( $r$ values) $N=2421$

\begin{tabular}{llll}
\hline & $\begin{array}{l}\text { Cereal fibre } \\
\text { intake }\end{array}$ & $\begin{array}{l}\text { Systolic blood } \\
\text { pressure }\end{array}$ & $\begin{array}{l}\text { Diastolic blood } \\
\text { pressure }\end{array}$ \\
\hline $\begin{array}{c}\text { Systolic blood } \\
\text { pressure }(\mathrm{mmHg})\end{array}$ & $-0.053^{* *}$ & & \\
$\begin{array}{c}\text { Diastolic blood } \\
\text { pressure }(\mathrm{mmHg}) \\
\begin{array}{c}\text { Heart rate } \\
\text { (beats/min) }\end{array}\end{array}$ & $-0.057^{* *}$ & $0.664^{* * * *}$ & \\
\hline$* * 071^{* * *}$ & $0.183^{* * * *}$ & $0.186^{* * * *}$ \\
\hline p $<0.01, \quad * * * \mathrm{p}<0.001, \quad * * * * * \mathrm{p}<0.0001$, &
\end{tabular}

Table 2 Mean (SD) systolic pressure, diastolic pressure, and heart rate stratified by quintile of cereal fibre intake

\begin{tabular}{|c|c|c|c|c|c|c|}
\hline \multirow[t]{2}{*}{$\begin{array}{l}\text { Quintile cereal } \\
\text { fibre intake } \\
\text { (g/day) }\end{array}$} & \multicolumn{2}{|c|}{$\begin{array}{l}\text { Systolic blood } \\
\text { pressure } \\
\text { (mmHg) }\end{array}$} & \multicolumn{2}{|c|}{$\begin{array}{l}\text { Diastolic blood } \\
\text { pressure } \\
(\mathrm{mmHg})\end{array}$} & \multicolumn{2}{|c|}{$\begin{array}{l}\text { Heart rate } \\
\text { (beats/min) }\end{array}$} \\
\hline & $N$ & Mean (SD) & $N$ & Mean (SD) & $N$ & Mean (SD) \\
\hline $\begin{array}{l}-4 \cdot 0 \\
4 \cdot 1-6 \cdot 0 \\
6 \cdot 1-8 \cdot 0 \\
8 \cdot 1-10 \cdot 4 \\
10 \cdot 5 \\
\text { Total }\end{array}$ & \begin{tabular}{|r|r|}
487 \\
508 \\
459 \\
482 \\
483 \\
2419
\end{tabular} & $\begin{array}{l}142.1(19.8) \\
141.0(19.5) \\
141.9(19.7) \\
140.4(18.9) \\
138.8(18.7) \\
140.8(19.3)\end{array}$ & $\begin{array}{r}487 \\
507 \\
459 \\
481 \\
483 \\
2417\end{array}$ & $\begin{array}{l}89.9(13.4) \\
88.4(12.5) \\
88.5(12.9) \\
88.5(12.9) \\
87.8(12.9) \\
88.7(12.9)\end{array}$ & $\begin{array}{r}486 \\
510 \\
460 \\
482 \\
483 \\
2421\end{array}$ & $\begin{array}{l}72.9(13.4) \\
72.0(11.4) \\
71.3(12.3) \\
71.2(11.8) \\
70.22(12.1) \\
71.5(12.2)\end{array}$ \\
\hline
\end{tabular}

Table 3 Mean (SD) systolic pressure, diastolic pressure, heart rate, and cereal fibre intake by employment status

\begin{tabular}{|c|c|c|c|c|c|}
\hline \multirow[t]{2}{*}{ Employment status } & $\begin{array}{l}\text { Systolic blood } \\
\text { pressure }\end{array}$ & $\begin{array}{l}\text { Diastolic blood } \\
\text { pressure }\end{array}$ & $\begin{array}{l}\text { Heart rate** } \\
\text { (beats/min) }\end{array}$ & \multicolumn{2}{|c|}{$\begin{array}{l}\text { Cereal fibre** } \\
\text { (g/day) }\end{array}$} \\
\hline & $N \quad \operatorname{Mean}(S D)$ & $N \quad \operatorname{Mean}(S D)$ & $N \quad \operatorname{Mean}(S D)$ & $N$ & Mean (SD) \\
\hline $\begin{array}{l}\text { Employed } \\
\text { Unemployed } \\
\text { Total }\end{array}$ & $\begin{array}{rrr}1968 & 141 \cdot 1 & (19 \cdot 3) \\
515 & 139 \cdot 3 & (19.8) \\
2483 & 140.7 & (19 \cdot 4)\end{array}$ & $\begin{array}{rrr}1968 & 88.8 & (12.8) \\
513 & 87.6 & (13.5) \\
2481 & 88.5 & (12.9)\end{array}$ & $\begin{array}{rll}1968 & 71.2 & (12.1) \\
517 & 73.1 & (13.3) \\
2485 & 71.6 & (12.4)\end{array}$ & $\begin{array}{r}1917 \\
487 \\
2404\end{array}$ & $\begin{array}{ll}7.8 & (4.6) \\
7.1 & (4 \cdot 2) \\
7.7 & (4.5)\end{array}$ \\
\hline
\end{tabular}

*** $\mathrm{p}<0.01$

Table 4 Mean (SD) systolic pressure, diastolic pressure, heart rate, and fibre intake by prevalent IHD

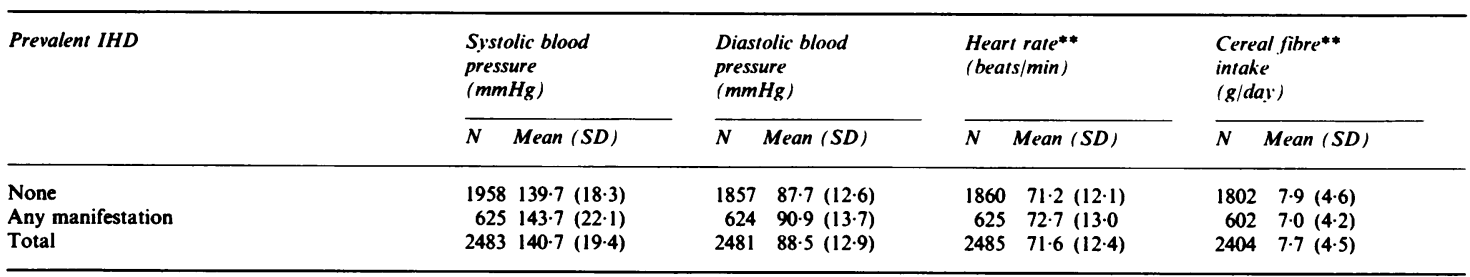

$* * 0.01$ 
Table 2 presents mean systolic pressure, diastolic pressure, and heart rate stratified by quintile of cereal fibre intake. Moving from the lowest to the highest quintile, mean systolic pressure decreased $3.3 \mathrm{mmHg}$, mean diastolic pressure decreased $2.1 \mathrm{mmHg}$, and mean heart rate decreased 2.7 beats $/ \mathrm{min}$.

The mean blood pressure, heart rates, and cereal fibre intakes for employed and unemployed groups are shown in table 3. Blood presures were similar for the two groups. The unemployed had significantly higher heart rates and lower cereal fibre intakes.

Unemployed men tended to have more illness than employed men. The prevalence of IHD was $38 \%$ in the unemployed compared with $21 \%$ in the employed group. The effect of prevalent IHD is shown in table 4. Persons with any manifestation of IHD had significantly higher blood pressure and heart rates but ate significantly less fibre. The association between employment, prevalent IHD, and cereal fibre intake is shown in table 5 . The unemployed men with prevalent IHD ate an average of $1.5 \mathrm{~g}$ cereal fibre less than employed men without IHD.

The effects of the confounding factors on the association between cereal fibre intake and blood pressure are shown in table 6. For the whole cohort, after adjustment for age alone, systolic pressure apparently changes $-0.221 \quad \mathrm{mmHg} \quad(95 \%$ $\mathrm{CI}=-0.338,-0.054)$ and diastolic changes -0.163 $\mathrm{mmHg}(95 \% \mathrm{CI}=-0.276,-0.050)$ for each gram of cereal fibre eaten daily. After further adjustment for body mass index, prevalent ischaemic heart disease, employment status, and heart rate the effect attributable to fibre diminishes to $-0.153 \mathrm{mmHg}$ systolic $(95 \% \mathrm{CI}=-0.315,0.010)$ and $-0.104 \mathrm{mmHg}$ diastolic $(95 \% \mathrm{CI}=0.212,0.005)$ for each gram of cereal fibre eaten daily. If the regression coefficients are examined by employment status the association is strengthened slightly in employed men and is nonexistent among the unemployed (table 6).

Table 5 Cereal fibre intake (g/day) by employment status and prevalent IHD

\begin{tabular}{|c|c|c|c|c|c|c|}
\hline \multirow{3}{*}{ Prevalent IHD } & \multicolumn{6}{|c|}{ Cereal fibre intake $^{* *}(\mathrm{~g} /$ day $)$} \\
\hline & \multicolumn{2}{|c|}{ Unemployment } & \multicolumn{2}{|c|}{ Employed } & \multicolumn{2}{|c|}{ Total } \\
\hline & $N$ & Mean (SD) & $N$ & Mean $(S D)$ & $N$ & Mean (SD) \\
\hline $\begin{array}{l}\text { None } \\
\text { Any manifestation } \\
\text { Total }\end{array}$ & $\begin{array}{l}301 \\
186 \\
487\end{array}$ & $\begin{array}{l}7.4(4.4)) \\
6.5(4.0) \\
7.1(4.2)\end{array}$ & $\begin{array}{r}1501 \\
416 \\
1917\end{array}$ & $\begin{array}{l}8.0(4.7) \\
7.3(4.3) \\
7.8(4.6)\end{array}$ & $\begin{array}{r}1802 \\
602 \\
2404\end{array}$ & $\begin{array}{l}27.9(4.6) \\
27.0(4.2) \\
47.7(4.5)\end{array}$ \\
\hline
\end{tabular}

** Differences between cells in the table are statistically significant $(p<0.01)$
Table 6 Regression coefficients (95\% confidence intervals) for changes in blood pressure associated with changes in cereal fibre intake ( $\mathrm{mmHg} / \mathrm{g}$ cereal fibre)*

\begin{tabular}{lll}
\hline & $\begin{array}{l}\text { Systolic blood } \\
\text { pressure }\end{array}$ & $\begin{array}{l}\text { Diastolic blood } \\
\text { pressure }\end{array}$ \\
\hline $\begin{array}{l}\text { Total cohort }(\mathrm{n}=2366)^{* *} \\
\text { cereal fibre intake }\end{array}$ & $-0.153(-0.315,0.010)$ & $0.104(0.212,0.005)$ \\
$\begin{array}{l}\text { Employed men }(\mathrm{n}=1902) \\
\text { cereal fibre intake }\end{array}$ & $-0.186(-0.363,-0.009)$ & $-0.111(-0.228,0.005)$ \\
$\begin{array}{l}\text { Unemployed men }(\mathrm{n}=462) \\
\text { cereal fibre intake }\end{array}$ & $-0.004(-0.415,0.407)$ & $-0.065(-0.347,0.218)$ \\
\end{tabular}

- Regression coefficients adjusted for age, body mass index, prevalent iscaemic heart disease, and heart rate.

* Regression coefficients also adjusted for employment status.

\section{Discussion}

The evidence relating blood pressure to cereal fibre intake is conflicting. Significant negative associations were shown in 94 volunteers, ${ }^{2}$ in 117 men, ${ }^{3}$ and in 300 . health-food shoppers ${ }^{4}$. Furthermore, a controlled triak among 57 subjects ${ }^{10}$ showed a fall in blood pressuret with a vegetarian diet which included a high cerea $\bar{P}$ fibre intake. On the other hand, no relation was found in 337 busmen and bank clerks, ${ }^{5}$ or in 112 maleू industrial workers, ${ }^{6}$ while a controlled trial showed no effect of cereal or other fibre on blood pressure in 62 subjects. ${ }^{11}$

One explanation of these conflicting findings is that previous studies have been too small to detect consistently a small relation between cereal fibre and blood pressure. A randomised trial of cereal fibre supplementation would require about 850 subjects in both the control and intervention groups to have an $80 \%$ chance of detecting a $3 \mathrm{mmHg}$ change in systolic blood pressure. Such a weak relation may be potentially important, however, since small reductions of blood pressure affect the risk of death and disability, ${ }^{1}$ and moderate amounts of cereal fibre may have fewer side effects than antihypertensive drug therapy.

An alternative explanation for the inconsistent findings is the effect of confounding factors, associated (positively or negatively) with both blood pressure and cereal fibre intake. For example, the level of physical conditioning is associated negatively with blood pressure and positively with cereal fibre intake, since the people who select whole grain foods tend to be more health-conscious than others. Thus vegetarians tend to be leaner than omnivores ${ }^{12} 13$ and probably take more exercise on average. Since diet is an integral part of a person's way of life, it is very difficult to separate its action from that of other factors associated with it. The larger the study, the greater the possibility is of distinguishing between the 
effects of dietary and other elements in the subjects' lives. The Caerphilly Study provided an opportunity to examine data from nearly 2500 men obtained during a survey of a town in South Wales.

Resting heart rate is an index of physical conditioning. Its relation to blood pressure and cereal fibre might reflect a tendency for health-conscious people to eat more fibre. If this were the sole explanation of the connection between blood pressure and cereal fibre, we might expect this association to disappear when heart rate is included in the multiple regression analysis. The association was no longer statistically significant in all subjects together when heart rate was included, but the relation reappeared when employed men were examined separately, that is, there was still a significant negative relation between cereal fibre intake and systolic blood pressure, independent of heart rate, in employed men. The absence of such a relation in the unemployed men may be attributed to their higher heart rates and greater prevalence of IHD. These non-dietary factors have a substantial effect on blood pressure and obscure any action of cereal fibre.

This study does not provide conclusive evidence as to whether cereal fibre affects blood pressure. The cross-sectional nature of the survey cannot account for any temporal relations between the two factors. For example, dietary habits may have changed in response to health or employment problems. The small correlation coefficients show that if the relation is causal it explains less than $1 \%$ of the variation in blood pressure within the population. The interrelations with heart rate and employment status provide a warning that there may be other confounding variables not considered in this study.

In spite of these problems, the relation between cereal fibre and blood pressure may still be important. Although small, the association was strengthened in employed men and persisted after adjustment for age, body mass index, prevalent IHD, and heart rate,
Future investigations of this association will have to account for the effects of employment, heart disease, and heart rate. Randomised trails, larger than those previously conducted, are needed to determine if the cereal fibre/blood pressure link is causal.

\section{References}

${ }^{1}$ Rose G. Strategy of prevention: lessons from cardiovascular disease. $\mathrm{Br}$ Med J 1981; 282: 1847-51.

2 Wright A, Burstyn PG, Gibney MJ. Dietary fibre and blood pressure. Br Med J 1979; 2: 1541-3.

${ }^{3}$ Fehily AM, Milbank JE, Yarnell JWG, Hayes TM, Kubiki AJ, Eastham RD. Dietary determinants of lipoproteins, total cholesterol, viscosity, fibrinogen, and blood pressure. Am J Clin Nutr 1982; 36: 890-6.

${ }^{4}$ Burr ML, Sweetnam PM, Barasi ME, Bates CJ. Dietary fibre, blood pressure and plasma cholesterol. Nutrition Research 1985; 5: 467-72.

${ }^{5}$ Morris JN, Marr JW, Clayton DG. Diet and heart: a postcript. Br Med J 1977; 2: 1307-14.

${ }^{6}$ Silman AJ. Dietary fibre and blood pressure. Br Med J 1980; 280: 250.

${ }^{7}$ The Caerphilly and Speedwell Collaborative Group. Caerphilly and Speedwell Collaborative Heart Disease Studies. J Epidemiol Comm Health 1984, 38: 259-62.

${ }^{8}$ Yarnell JWG, Fehily AM, Milbank JE, Sweetnam PM Walker GL. A Short Dietary Questionnaire for use in an epidemiological survey: comparison with weighed dietary records. Hum Nutr: Appl Nutr 1983; 37A: 103-12.

${ }^{9}$ Armitage P. Statistical methods in medical research. Oxford: Blackwell Scientific Publication, 1971.

${ }^{10}$ Rouse IL, Beilin LJ, Armstrong BK, Vandogen R. Blood pressure lowering effect of a vegetarian diet: controlled trial in normotensive subjects. Lancet 1983; 1: 5-10.

11 Brussaard JH, Van Raaij JMA, Stasse-Wolthuis M, Katan MB, Hautvast JGAJ. Blood pressure and diet in normotensive volunteers: absence of an effect of dietary fibre, protein or fat. Am J Clin Nutr 1981; 34: 2023-9.

12 Sacks FM, Castelli WP, Donner A, Kass E. Plasma lipids and lipoproteins in vegetarians and controls. $N$ Engl J Med 1975; 292: 1148-51.

${ }^{13}$ Burr ML, Bates CJ, Fehily AM, St Leger AS. Plasma cholesterol and blood pressure in vegetarians. J Hum Nutr 1981; 35: 437-41. 